\title{
The trisomy (5)(q31-qter) syndrome: study of a family with a $\mathrm{t}(5: 14)$ translocation
}

\author{
A C ELIAS-JONES, ${ }^{*}$ P HABIBI, ${ }^{*}$ V F LARCHER, ${ }^{*}$ T SPENCER, $\dagger$ AND L J BUTLER $\dagger$ \\ ${ }^{*}$ Department of Paediatrics and the TRegional Cytogenetics Unit, Queen Elizabeth Hospital \\ for Children, London
}

SUMMARY We report a child with multiple malformations caused by trisomy for the distal part of the long arm of chromosome No 5. A neonatal diagnosis of Down's syndrome had previously been made on the basis of clinical examination and the detection of an additional chromosome not unlike No 21. A subsequent clinical re-evaluation, with the cooperation of the parents who permitted further studies, led to the confirmation of the true diagnosis. The mother was the carrier of a balanced translocation between chromosome No 5 and No 14. The child had severe growth and psychomotor retardation and characteristic features: microcephaly, antimongoloid slant, epicanthus, low set ears, downturned mouth, and long upper lip. She was hypertonic and a congenital heart disease (atrial septal defect) was present. We have compared this case with others known to be trisomic for segment 5q31-qter.

Though increasing numbers of patients with small chromosomal duplications and deficiencies are being shown by improvements in G-banding resolution, compared with classical trisomics and major deletions, they remain small in total. There are also appreciable differences in frequency, presumably related to potential viability, between different duplications of even the same chromosomes. Thus in chromosome No 5 there are far more partial trisomies for $5 \mathrm{p}$, a well recognised syndrome, compared with duplications of the long arm (5q). Less than 20 such cases have ever been discovered ${ }^{1}$; all except three represented trisomies for the terminal zone. We recently carried out a re-evaluation of a child who had been studied in the neonatal period and she proved to be mostly trisomic for the distal part of $5 \mathrm{q}$ (q31 to qter); this resulted from a balanced $t(5: 14)$ translocation in the mother. There are only seven cases from five families in the literature with the same duplication, all of them involved different translocation combinations from the case reported here. ${ }^{2-6}$

\section{Case report}

A girl, now aged 3 years, was the fourth child of the second marriage of an English mother and Gambian father. Her three male siblings were all clinically normal; the mother's fourth pregnancy ended in miscarriage. The first marriage resulted in three male children, all now adopted, the youngest of whom had congenital hydrocephalus and polydactyly.

The propositus was born at term after a normal pregnancy. Birth weight $(2200 \mathrm{~g})$, length $(43 \mathrm{~cm})$, and head circumference $(32 \mathrm{~cm})$ were all well below the third centile. Her facial appearance was unusual with a slight mongoloid slant of the palpebral fissures. She had a large umbilical hernia and there was a $2 / 6$ ejection systolic murmur at the mid sternal edge. In the neonatal period she had had two episodes of cyanosis and breathlessness during feeds. Although the electrocardiogram was normal, the chest radiograph showed slight enlargement of the cardiac silhouette and mild pulmonary plethora. A subsequent cardiac assessment using echocardiography showed a secundum atrial septal defect. Treatment was commenced with digoxin and diuretics.

A chromosome analysis performed soon after birth indicated the presence of an extra chromosome similar in size and morphology to No 21 though the centromere region differed slightly. A pericentric inversion of chromosome No 9 was also present and blood samples from both parents were requested. These were not forthcoming and in view of the clinical and chromosome appearance a working diagnosis of Down's syndrome was made.

Further studies were not possible until she was aged 20 months when she was admitted to this 
hospital for investigation of severe failure to thrive and developmental delay. Her height, weight, and head circumference had remained well below and were falling further from the third centile (fig 1). Her facies were unusual but were basically lacking the more important positive stigmata of Down's syndrome, and the slope of the narrow palpebral fissures was now somewhat antimongoloid (fig 2). There was a right epicanthic fold, and the upper lip was long and associated with a slightly downturned mouth. The ears were small and low set. The hair was rather sparse and there was widespread excoriated eczema. The lower limbs were spastic with hypertonia and scissoring. A large umbilical hernia containing bowel was still present and the cardiac signs remained unchanged.

\section{Investigations}

Skull radiography showed premature fusion of the saggital and lambdoid sutures, but a computed tomogram was normal. The bone age was retarded (12 months). Audiology showed a bilateral mixed hearing deficit.

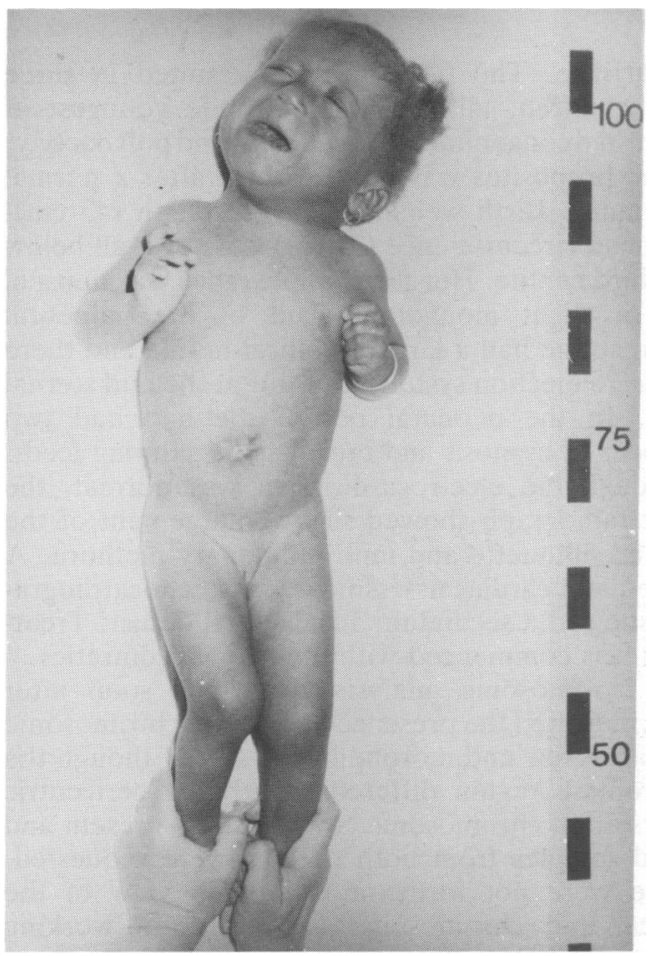

Fig 1 Patient aged 21 months showing repaired umbilical hernia and poor growth.

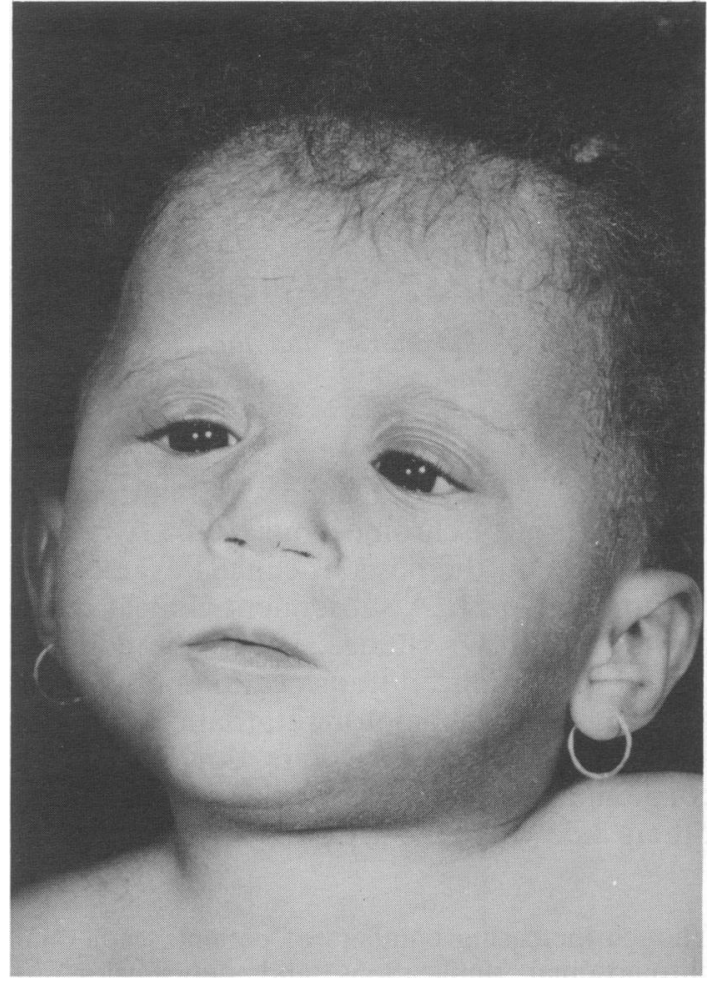

Fig 2 Patient aged 21 months showing narrow palpebral fissures, dysmorphic facial appearance, and the sparse hair.

Results of biochemical and haematological investigations showed no evidence of malabsorption. Renal, adrenal, liver, and thyroid function tests gave normal results. Plasma and urine amino acid profiles were normal as were serum concentrations of trace metals including iron, zinc, and copper. A dermatoglyphic study showed an unusual combination of patterns consistent with a chromosome abnormality but not Down's syndrome. Six out of 10 digits had simple arch patterns and a distal $t$ triradius was present on the right hand (fig 3) but not on the left. The D line exit was in the fourth interspace on the right, but the $\mathrm{d}$ triradius was absent on the left. There were no patterns on the thenar, hypothenar, and hallucal areas except for a small hypothenar loop on the right palm.

\section{Cytogenetics}

The opportunity was taken to study the patient further, and also to karyotype both parents. The centromere region of the additional acrocentric chromosome was different from the other $\mathrm{G}$ group 
chromosomes by virtue of a very small pale sub centromeric region in the long arm thus indicating that it was a translocation product. The distal segment of the long arm including the dense band, though similar to No 21 , probably represented the terminal region of another autosome ending in a very

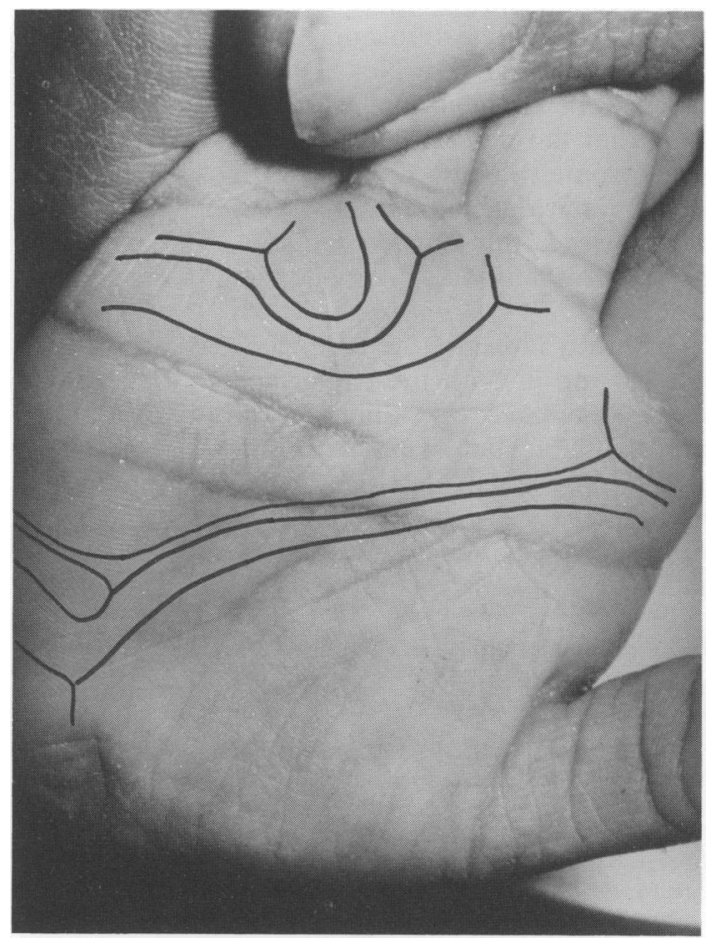

Fig 3 Palmar creases and dermatoglyphic patterns (right hand). pale telomere. The mother was found to have the same recombinant chromosome as her daughter, replacing a No 14, and this had resulted from a balanced translocation between No 14 and the terminal part of long arm No 5, the break points being respectively $\mathrm{q} 11$ and $\mathrm{q} 31$. (46,XX,t $(5: 14)$ (q31:q11)) (fig 4). The ovum at conception therefore contained a normal haploid set of 23 chromosomes together with the small recombinant chromosome. The father was the carrier of the No 9 with the pericentric inversion $(46, X Y$, per.inv. 9$)$.

The propositus therefore resulted from a $3: 1$ segregation from the chain quadrivalent formed at pachytene in maternal meiosis. She is trisomic for the centromere region of No 14 and the segment q31 to qter of chromosome No 5. The three male siblings were all proved to be carriers of the same balanced translocation. It has not been possible to karyotype the three half siblings of the first marriage.

\section{Progress and management}

Her eczema responded dramatically to a diet free of milk and eggs. Treatment with digoxin and diuretic was continued and the umbilical hernia was repaired surgically. By the age of 25 months her speech was limited to short monosyllabic babble and there was moderate to severe hearing loss. Her Griffiths's scale performance was rated as 'general' 2 months, 'hand/eye coordination' 6 months, and 'social' 7 months.

A year later (aged 3 years 1 month) she was sitting unaided, walking with gaiters, and able to roll over. She could say two words and was finger feeding. However, she remained clearly microcephalic and dysmorphic in appearance with hypertonia.

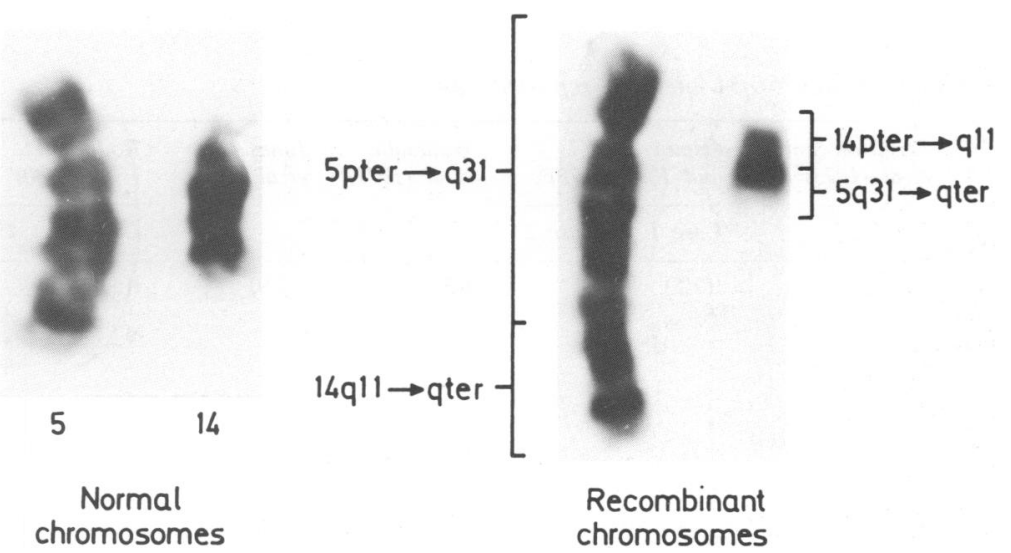

Fig 4 Partial karyotype of mother showing a reciprocal interchange between chromosome Nos 5 and 14 with the break points as indicated $(\times 10000)$. Her daughter therefore received from her the small recombinant chromosome additional to a normal haploid set. 


\section{Discussion}

Though this child had a superficial resemblance to a child with Down's syndrome in the newborn period, detailed appraisal of her clinical features during her second and third years of life have established firm similarities with other patients having a proven duplication of the terminal region from band 31 of the long arm of chromosome No 5. The main malformations of a total of eight cases, including this case, are reviewed in the table. ${ }^{2-6}$ In the series there is a predominance of females (seven female:one male). The average maternal age was not increased as all the cases resulted from familial translocations. All were of low birth weight with evidence of intrauterine growth retardation and growth that continued to fall away from below the third centile. Severe psychomotor retardation with deafness was soon apparent. Recorded cases are microcephalic with distinctive facies including antimongoloid slant of narrow palpabral fissures. Most have epicanthus and hypertelorism; strabismus may be present. The mouth is somewhat small and downturned with a rather long upper lip. The ears are usually low set and often large. There may be minor digital anomalies and there is a high frequency of cardiac malformation. The child described here therefore represents a typical example of the syndrome. Some variation in the clinical appearance is to be expected, however, in view of the different chromosomes involved with No 5 in the rearrangements. The age at the time of reporting in the previous cases varied from the newborn to 4 years and all were alive at the time..$^{2-6}$

The results of chromosome segregation in this family will lead to normal and balanced carriers from regular alternate segregation in maternal meiosis, but grossly unbalanced and potentially non-viable zygotes will result from adjacent segregation because the size of the duplication and deficiency anomalies are so large. A 3:1 segregation of the normal No 5 and No 14 chromosomes with the small recombinant chromosome, however, represents only a small duplication and is presumably viable. Complete trisomics for Nos 5 and 14 from other 3:1 segregations are again not viable. On this basis it is likely that the defective half brother has the same chromosome imbalance as the propositus. Though clearly indicated, prenatal screening of future pregnancies in this family is unlikely as the mother is against termination of pregnancy under any circumstances.

This study indicates the importance of persistence in follow up in both the clinics and the laboratory despite initial lack of cooperation on the part of the parents. Only when samples from the parents were forthcoming, coupled with a re-evaluation of the child's karyotype and clinical signs including dermatoglyphics, could a definitive diagnosis be made.

We are grateful to Mrs Karen Spencer for secretarial help.

\section{References}

${ }^{1}$ Gilgenkrantz S, Dulucq P, Bresson JL, Gouget A, Pernot C, Gregoire MJ. Partial proximal trisomy of the long arm of chromosome $5(\mathrm{q} 13-\mathrm{q} 22)$ resulting from maternal insertion der ins (10:5). J Med Genet 1981;18:465-80.

2 Ferguson-Smith MA, Newman BF, Ellis PM, Thompson DMG, Riley IO. Assignment by deletion of human red cell acid phosphatase gene locus to the short arm of chromosome 2 . Nature 1973;243:271-4.

${ }^{3}$ Osztovics M, Kiss P. Familial translocation t(2:5)(p28:q31). Clin Genet 1975;8:112-6.

Table Clinical features of trisomy 5(q31-qter) in reported cases

\begin{tabular}{|c|c|c|c|c|c|c|c|c|}
\hline & \multirow[t]{2}{*}{$\begin{array}{l}\text { Ferguson-Smith } \\
\text { et al }(1973)^{2}\end{array}$} & \multicolumn{2}{|c|}{$\begin{array}{l}\text { Osztovics } \\
\text { and Kiss }(1975)^{3}\end{array}$} & \multirow[t]{2}{*}{$\begin{array}{l}\text { Watanabe } \\
\text { et al }(1977)^{4}\end{array}$} & \multirow[t]{2}{*}{$\begin{array}{l}\text { Jones } \\
\text { et al }(1979)^{5}\end{array}$} & \multicolumn{2}{|c|}{$\begin{array}{l}\text { Rodewald } \\
\text { et al }(1980)^{6}\end{array}$} & \multirow[t]{2}{*}{$\begin{array}{l}\text { Present } \\
\text { case }\end{array}$} \\
\hline & & Case 1 & Case 2 & & & Case 1 & Case 2 & \\
\hline Familial translocation & $t(2: 5)$ & $t(2: 5)$ & & $t(5: 13)$ & $t(5: 9)$ & $t(5: 11)$ & & $t(5: 14)$ \\
\hline Growth retardation & + & + & + & & + & + & + & + \\
\hline Psychomotor retardation & + & + & + & & & + & + & + \\
\hline Antimongoloid slant & + & & & & & + & & + \\
\hline Epicanthus & & + & + & + & & & + & + \\
\hline Hypertelorism & + & + & & & & + & & \\
\hline Strabismus & & + & + & & & + & & \\
\hline Long upper lip & & + & & & + & & & + \\
\hline Downturned mouth & & & & & & + & & + \\
\hline Micrognathia & & & & & + & + & + & \\
\hline Low set ears (large) & + & + & + & & & + & + & $(+)$ small) \\
\hline
\end{tabular}


The trisomy (5)(q31-qter) syndrome: study of a family with a t(5:14) translocation 431

${ }^{4}$ Watanabe G, Kiyoi Y, Takeyama I, Kawana S, Yamamoto H. Inherited chromosomal translocation in two females $\mathrm{t}(4 \mathrm{q}-: 13 \mathrm{q}+)$ and $\mathrm{t}(5 \mathrm{q}-: 13 \mathrm{q}+)$. Tohoku J Exp Med 1977;121: $179-84$.

5 Jones LA, Jordan DK, Taysi K, Strauss AW, Toth JK. Partial duplication of the long arm of chromosome 5: a case due to balanced paternal translocation and a review of the literature. Hum Genet 1979;51:37-42.

${ }^{6}$ Rodewald A, Kankl M, Gley EO, Zano KD. Partial trisomy 5q: three different phenotypes depending on different duplication segments. Hum Genet 1980;55:191-8.

Correspondence to Dr LJ Butler, NE Thames Regional Cytogenetics Unit, Queen Elizabeth Hospital for Children, Hackney Road, London E2 8PS.

Accepted 15 October 1987 